\title{
Optimal Operation of Micro-Grids to Reduce Energy Production Costs and Environmental Pollution Using Ant Colony Optimization Algorithm (ACO)
}

\author{
Giulio Lorenzini ${ }^{1}$, Mehrdad Ahmadi Kamarposhti ${ }^{2 *}$, Ahmed Amin Ahmed Solyman ${ }^{3}$ \\ ${ }^{1}$ Department of Industrial Engineering, University of Parma, Parco Area Delle Science 181/A, 43124 Parma, Italy \\ ${ }^{2}$ Department of Electrical Engineering, Jouybar Branch, Islamic Azad University, Jouybar, Iran \\ ${ }^{3}$ Department of Electrical and Electronics Engineering, Faculty of Engineering and Architecture, Istanbul Gelisim University, \\ Istanbul, Avc1lar 34310, Turkey
}

Corresponding Author Email: mehrdad.ahmadi.k@gmail.com

https://doi.org/10.18280/jesa.540102

Received: 5 November 2020

Accepted: 24 February 2021

\section{Keywords:}

distributed generation, microgrid, resources of energy distribution, ant colony optimization algorithm, renewable energy source, reducing cost, reducing pollution

\begin{abstract}
With increasing demand for electric energy and requesting higher quality by subscribers, the electric power industry has moved towards using new technologies. Many modern societies seek to use the systems of new energy management in order to reduce environmental pollutants and operational costs in electrical energy systems. Therefore, exploiting various resources of renewable energies, micro-grids can be considered as a significant tool to attain these objectives. According to the subject, Ant Colony Optimization algorithm (ACO) is used in this paper to optimize one micro-grid sample in order to reduce the cost of generating power and to reduce environmental pollution to increase reliability. The recommended algorithm has been done in two scenarios and each in two sections. In the first scenario, energy management will be conducted for all distributed generation resources and in the second scenario it is assumed that wind and solar products, produce their maximum power and energy management are conducted for the reminder elements and the results are compared with other optimization algorithms.
\end{abstract}

\section{INTRODUCTION}

Vast usage of fossil fuels such as oil, coal and gas are accompanied with greenhouse effects and pollution of environment. Meanwhile, there is a great conflict between the resources of fossil fuel and energy demand in the world. Energy deficit and environment pollution have been main obstacles for human development. On the other hand, with the growth in electric consumption and demand for higher quality of the consuming power, electricity industry has led into using new technologies. Using distributed products technology to generate electricity is one of the ways that is recommended to cover the challenges ahead, especially environmental concerns. Limitation of fossil fuels and air pollution are the main stimulus of developing this technology. Generating electricity near the consumption location, not only can reduces the loss in system, but also can create more flexibility to deliver various service for the consumers. Increasing the penetration of distributed generation resources in the electric grids and considering different technologies, uncertainties of its renewable types as well as converting inactive distribution grid into active distribution grids are considered as main challenges to design power systems in future.

One of the viewpoints which is recommended for the effective increase of participation for these resources is to integrate these resources with the objectives of visibility, suitable relation between these resources and electric grid as well as controlling these resources more efficiently. One of the ways of integrating the distributed generation resources is a new concept called microgrid. Microgrids are low voltage or medium voltage active distribution grids that consist a set of loads, distributed generation resources and controlling instrument. Due to independence in exploitation, these grids can take apart the main grid and be used as island. In fact, the main objective of forming these grids is the technical problems related to increase reliability and quality of electricity delivered to the consumers.

Therefore, in the viewpoint of upstream grids microgrid is on element with double property that is sometimes considered load and sometimes generation resource. Independence in exploitation is the main property of microgrids, some duties will be considered by the exploiter of the microgrid. Microgrid exploiter is obligated to maintain the security of these grids and providing the needed lateral service for secure exploitation.

On the other hand, necessary stimuli should be generated economically for energy generation resources so that such grids can be established with high penetration of distributed generation resource. It should be considered that company of distributed generation resources individually makes some limitations economically and technically in electric markets and in the related lateral service that their integration in microgrid can somehow resolve these limitations. In the future, by developing microgrids, active distribution grids consist of microgrids and distributed generation resources, breakable and unbreakable loads, will be generated. These grids, which are also called multiple microgrid in resources, should perform the necessary strategies for independent exploitation of upstream grids themselves. In fact, the multiple microgrids exploiters should provide the necessary technical and economic strategies for the optimal usage from resources.

With this perspective, microgrids and multiple microgrids exploiters and obligated to perform a set of duties which not 
only ensure system security, but also make its grids members satisfied. So, they should perform planning with the objective of resources satisfaction and its over ally controlled system loads by considering all technical and economical provisions as well as potential relation with upstream markets.

In conventional grids, electric power needed for consumer is generated as integrated and in the farther distance from consumer, which this has manifested some problems, such as high cost of building power plant and transfer lines in higher capacity as well as high loss of such grids. Low reliability is the other defect of conventional grids because while occurring error and disconnection of transfer lines, there is a possibility that more consumers left without electricity. Therefore, in order to overcome such problems, distributed generation has attracted more attention.

Increasing the demand of electric energy and requesting higher quality on behalf of subscribers, power industry has been led to modern technologies. On the other hand, the increasing procedure of individualization power market competitiveness and converting large investors to small investors, have made the power industry managers to pay attention into increase the generation power and grid elements with maximum energy efficiency and minimum exploitation cost.

Microgrids which are the merge of renewable and unrenewable energy to feed electrical and thermal loads, are suitable for rural regions, industrial units, town and specially the cases in which there is concurrent usage of heat and power (CHP). In fact, microgrid is a set of loads and generators that can work as island or connected to the grid. Due to low load and the nature of microgrid, microgrid generators are generally as generators with distributed resources. These resources can be solar cells, wind turbine, micro turbine, battery, etc. Among the other advantages of using microgrid, we can refer to decrease in the cost of power generation and deterioration. This is realized when there is a correct management on microgrid power.

Due to the mentioned problem of conventional grids, the tendency towards distributed generation and specially microgrids has been increased. But the problem that is significant is the subject of energy management in microgrid. There are some resources of power generation and saver resources that each has its power generation cost, pollution and specific limitations. These resources should be controlled so that the costs of energy generation as well as environmental pollutions should be minimized in them by considering the limitations.

The objective of this paper is to attain a comprehensive program for exploiting microgrids and considering the existent capacity in power market. The exploiter should select a pattern to use microgrid are considered includes power generation resources and load. On the other words, an approach should be recommended that grid loads be confident of providing its needed energy with high reliability and power quality and to minimize the costs of energy generation and the pollutions made by microgrid. To attain this, different methods have been conducted in the research that we will refer to some of them in the next section.

In this paper, in order to attain a comprehensive planning about utilizing microgrid based on the ability of power market, Ant Colony Optimization (ACO) algorithm has been used. The algorithm that has high convergence speed and high accuracy can help us to attain our goals. By considering generation limitations of each generation equipment of energy sever, the given algorithm has been codified. In this paper, two scenarios will be considered:

-Minimize the cost of power generation;

-Minimize pollution.

In the following the second section, a review on the conducted research will be done about utilizing microgrid. In the third section, modelling the studying subject, objective function and problem limitations will be represents in this section. In the fourth section, ACO algorithm will be explained briefly to solve problem. Simulation results will be presented in two scenarios and a comparison will be done between the results obtained of simulation by ACO algorithm and the results of other papers. Finally, the paper ends with the presentation of the results in the sixth section.

\section{A REVIEW ON THE CONDUCTED RESEARCH ABOUT UTILIZING MICROGRID}

A vast research has been done in the field of new energies, distributed generations also microgrids that in this section, it is refer to some papers that are in line with the goal of the paper. A review on the conducted research about microgrid can be seen in the references [1-4].

In order for short-term planning and exploiting microgrids, at first the structure of exploitation and controlling the microgrids should be mentioned that has the duty of exploiting these grids [5]. Despite the resources such as low voltage microgrids, resources of distributed generation with larger size and a set of breakable and unbreakable loads, distribution grids are defined by a concept such as multiple microgrids [6].

It has dealt with reviewing types of modelling methods and energy management in microgrid [7]. In this paper, the research conducted in this type of microgrids have been reviewed.

A predictive model has been used to have a microgrid with high reliability [8]. Other objective of this paper is to reduce power generation in a microgrid. Similarly, this method has been used for optimization in a microgrid practically [9]. In details of planning a microgrid has been decreased based on decentralized strategy [10]. Planning a microgrid has been modelled for each resource and loads in order to maximize the income of distributed generation resources by defining some factors for trading [11]. Some methods have been presented for company and modelling market mechanisms [12]. Based on a multi-factor method [13], a 24 hours planning has been performed for microgrid that the relation among the hours of exploitation has not been considered.

By considering a microgrid as a factor in multiple microgrid separate from the grid [14], a 24-hours plan has been performed, at first to minimize the generation cost by considering the cost of turning the units on and off and providing internal load. Then, suitable values have been extracted to recommend in multiple microgrid market.

The problem of optimization in the state of island has been presented for a time interval $[15,16]$. Eslami and Ahmadi Kamarposhti studied the optimal design of a grid-connected the hybrid energy system for a sample area in the north Iran [17]. A new innovative cost-based objective function is proposed which is combination of life cycle cost and reliability cost. Also, loss of power supply probability (LPSP) criteria, is considered as constraint for ensuring at the same time certain level of system reliability [17]. 
An objective function has been minimized based on generation costs, pollution costs, exploitation costs and repairs [18]. In addition to maximize the income of generation resources of selling energy and economical studies, optimization with the objective of reducing pollution and towards environmental objectives in microgrid.

A linear programming has been used for optimal control of a home microgrid and has evaluated the value of economic efficiency while using microgrid in the building [19]. By considering a possible function for wind and solar generations, have conducted the microgrid energy management [20].

In grid connected mode, voltage and frequency of microgrid is controlled by main grid and DG's supply total or part of the loads. In the islanding mode, the microgrid is disconnected from main grid because of a fault or a preplanned switching in connecting line. In this mode, DG's should satisfy the power demand of sensitive loads in microgrid. Since the only generation units in an islanded microgrid are existing DG units which usually are from several types [21].

Through using the mixed integer nonlinear programming (MINLP) and by the objective of minimizing the objective function which include investment costs, exploitation, repair, maintenance and environmental, optimizes the microgrid exploitation [22]. In order for short-term programming and exploiting microgrids at first exploitation structure and controlling microgrids are posed which has the duty of exploiting these grids. With the existence of resources such as low voltage microgrids, distributed generation resources with larger size and a set of breakable and unbreakable loads, distribution grids are defined with the concept such as multiple microgrids [23]. It has dealt with reviewing the types of modelling methods and energy management in microgrid [24]. In this paper, the research conducted about this kind of microgrids have been reviewed. A predictive model has been used to have a microgrid with high reliability [25]. The other objective of this paper is to decrease power generation cost in a microgrid. Similarly, this method [26] is used for optimization in a microgrid practically in the ref. [27], details of programming a microgrid have been discussed based on a decentralized strategy. The programming a microgrid has been modelled for each resource and repeatedly in order to maximize the income of distributed generation resources by the definition of factors for trading [28]. Some methods have been presented for the company and modelling market mechanisms for microgrids [29]. Based on a multi-factor method [30], a 24-hour programming has been performed for microgrid that the relation between exploitation time has not been considered. By considering each microgrid as a factor in a multiple microgrid separate from the grid [31], a 24-hour program has been performed firstly to minimize the generation cost by considering the cost of turning the units on and off and providing internal load. Then suitable values have been extracted for recommendation in the market of multiple microgrid. The problem of optimization in the island state has been presented for a 1-hour interval [32]. Daily programming has been presented to optimize a microgrid without communication among different hour of its programming in the island state [33]. In addition to maximize the income of generation resources from purchasing energy and economical studies [34], optimization has been performed with the objective of reducing pollution and towards environmental objectives. An objective function has been minimized based on generation costs, pollution cost, exploitation and repair cost [35]. In this microgrid, the strategy has been modelled based on providing load by internal resources and battery. The linear programming has been used for optimal control of a home microgrid, and the value of economic saving has been evaluated while using microgrid in building [36]. The energy of distributed generation resources has been managed in the presence of hydro genic savers [37]. In this reference a probabilistic model for each resource and load. Then seeking optimization change was done through self-adaptive algorithm. The results imply more suitable performance of this algorithm than the particles integration algorithm.

In this paper, ACO optimization algorithm will be used to attain a comprehensive programing about exploiting microgrid based on the capability of power market. This algorithm with high convergence speed and high accuracy, can help us to attain our objectives.

\section{PROBLEM MODELLING}

By considering generation limitations of each generation equipment's or energy storage, the given algorithm has been coded. In this paper, two objective functions have been considered:

-Minimize power generation cost;

-Minimize pollutions.

\subsection{First objective (decrease power generation costs)}

Operational costs that the studying microgrid faced with includes: fuel cost, step up cost, power exchange cost, etc. Eq. (1) can be used for this objective.

$$
\begin{gathered}
\text { Cost }=\sum_{t=1}^{t=24}\left(\sum_{n=1}^{s_{g}}(A)+\sum_{m=1}^{s_{r}}(B)\right. \\
\sum_{n=1}^{s_{g}}(A)=\left[k n(T) P^{g n}(T) B^{g n}(T)+S^{g m}[K n(T)-\right. \\
\left.K n(T-1)]+P^{g r i d}(T) B^{g r i d}(T)\right] \\
\sum_{m=1}^{s_{r}}(B)=\left[K m(T) P^{s m}(T) B^{s m}(T)+\right. \\
S^{s m}\left[K m(T)-K m(T-1)+P^{g r i d}(T) B^{g r i d}(T)\right]
\end{gathered}
$$

in which, $\mathrm{P}^{\mathrm{gn}}(\mathrm{T}), \mathrm{B}^{\mathrm{gn}}(\mathrm{T})$ are the recommended values for distributed generation resource and energy storage devices in time $\mathrm{T}$.

$\mathrm{P}^{\mathrm{sm}}(\mathrm{T})$ and $\mathrm{B}^{\mathrm{sm}}(\mathrm{T})$ represent the cost of start and end for $\mathrm{nth}$ distributed generation resource and $m$ th energy storage generator. $\mathrm{P}^{\text {grid }}(\mathrm{T})$ is the bought energy from the grid or sold to the grid in time T. $B^{\text {grid }}(\mathrm{T})$ represents the used energy in time T. X variables are vector and includes active forces of units and the states related to them which is expressed as follows:

$$
\begin{gathered}
Y=\left[P^{G}\right] \\
P^{G}=\left[P^{g}, P^{s}\right] \\
k=s_{g}+s_{r}+1
\end{gathered}
$$

in which, $\mathrm{n}$ is the number of state variables, $\mathrm{S}_{\mathrm{g}}, \mathrm{S}_{\mathrm{r}}$ number of whole generation units and units of energy storage. $P_{g}$ is vector power that includes active powers in all DGs. These variables are defined as follow:

$$
\begin{gathered}
P^{g}=\left[P^{g 1}, P^{g 2}, \ldots, S_{r}\right] \\
P^{g 1}=\left[P^{g n}(1), P^{g n}(2), \ldots, P^{g n}(t), \ldots, P^{g n}(T)\right] \\
P^{s}=\left[P^{s 1}, P^{s 2}, \ldots, S_{g}\right] \\
P^{s m}=\left[P^{g s m}(1), P^{s m}(2), \ldots, P^{s m}(T)\right]
\end{gathered}
$$


which, in the Eq. (5), T represents the number of all hours, $\mathrm{P}^{\text {grid }}(\mathrm{T})$ and $\mathrm{P}^{\mathrm{sm}}(\mathrm{T})$ are the value of output power of ith generator and jth energy storage in the time $t$.

\subsection{Second objective (decrease of pollution emission)}

In the second step, by considering the effect of pollution emission as the second objective, has been considered the most important pollutants related to distributed generation resources in the microgrid, namely $\mathrm{NO}_{x}, \mathrm{CO}_{2}$ and $\mathrm{SO}_{2}$. The objective function related to pollution can be expressed as follow [38].

$$
\begin{gathered}
\text { Emission }=\sum_{t=1}^{T} \operatorname{Emission}(t)=\sum_{t=1}^{T}\left[\sum_{n=1}^{s_{g}}(A)+\right. \\
\left.\sum_{m=1}^{s_{r}}(B)\right] \\
\sum_{n=1}^{s_{g}}(A)=\left[k n(T) P^{g n}(T) E^{g n}(T)+\right. \\
\left.P^{g r i d}(T) E^{g r i d}(T)\right] \\
\sum_{m=1}^{s_{r}}(B)=\left[K m(T) P^{s m}(T) E^{s m}(T)+\right. \\
\left.P^{\text {grid }}(T) E^{g r i d}(T)\right]
\end{gathered}
$$

In the above equation, $E^{g m}(T), E^{s m}(T)$ and $E^{\text {grid }}(T)$ the value of pollution emission has been considered in $\mathrm{Kg} / \mathrm{MWh}$ for each distributed generation unit in time t. these variables are defined as follow:

$$
E^{g n}(t)=N O_{x}^{D G n}(t)+C O_{2}^{D G n}(t)+S O_{2}^{D G n}(t)
$$

in which, $\mathrm{CO}_{2}{ }^{\mathrm{DGn}}(\mathrm{t}), \mathrm{SO}_{2}{ }^{\mathrm{DGn}}(\mathrm{t})$ and $\mathrm{NO}_{\mathrm{x}}{ }^{\mathrm{DGn}}(\mathrm{t})$ are the value of $\mathrm{CO}_{2}{ }^{\mathrm{DGn}}, \mathrm{SO}_{2}{ }^{\mathrm{DGn}}$ and $\mathrm{NO}_{\mathrm{x}}{ }^{\mathrm{DGn}}$ that from ith DG are spread in the time $\mathrm{t}$.

$$
\begin{gathered}
E^{\text {sm }}(t)=N O_{x}^{\text {Storage }}{ }^{m}(t)+\mathrm{CO}_{2}^{\text {Storage }}{ }^{m}(t)+ \\
\mathrm{SO}_{2}^{\text {Storage }}{ }^{m}(t)
\end{gathered}
$$

in which, $\mathrm{CO}_{2}$ storage $\mathrm{m}(\mathrm{t}), \mathrm{SO}_{2}$ storage $\mathrm{m}(\mathrm{t})$ and $\mathrm{NO}_{\mathrm{x}}$ storage $\mathrm{m}(\mathrm{t})$ are the value of $\mathrm{CO}_{2}{ }^{\text {storage } \mathrm{m}}, \mathrm{SO}_{2}{ }^{\text {storage } \mathrm{m}}$ and $\mathrm{NO}_{\mathrm{x}}$ storage $\mathrm{m}$ that from $\mathrm{jth}$ storage are spread in the time $\mathrm{t}$.

$$
E^{\text {grid }}(t)=N O_{x}^{\text {grid }}(t)+C O_{2}^{\text {grid }}(t)+S O_{2}^{\text {grid }}(t)
$$

In the Eq. (11), $\mathrm{CO}_{2}{ }^{\text {grid }}(\mathrm{t}), \mathrm{SO}_{2}{ }^{\text {grid }}(\mathrm{t})$ and $\mathrm{NO}_{\mathrm{x}}{ }^{\text {grid }}(\mathrm{t})$ are the value of $\mathrm{CO}_{2}{ }^{\text {grid }}, \mathrm{SO}_{2}{ }^{\text {grid }}$ and $\mathrm{NO}_{\mathrm{x}}{ }^{\text {grid }}$ resulted from the grid in the time $\mathrm{t}$.

\section{ANT COLONY OPTIMIZATION ALGORITHM}

Ant Colony Optimization algorithm (ACO) has been known as Ant colony algorithm and Ant colony optimization. This method is derived from real movement of ants in the nature that was introduced in Marco Dorigo's $\mathrm{PhD}$ thesis for the first time in 1990 under the title of Ant system. The behavior of ants in their colony is more directed towards maintaining colony survival. One of the most important and interesting research is related to the behavior of organisms such as ants that are blind animals, the way of finding their food and the least path of their colony to food source. This type of behavior has a type of aggregative intelligence that has been attracted scientist attention recently. In Ant colony algorithm, particles seek a limited number of artificial ants that exploit stigmergic relation. It means that a form of indirect relation is used by the surroundings to make the answers for the given problem.
After observing the complete behavior of ants and practical studies, it is concluded that all ants leave a matter named Pheromone while walking. The value of secretion is completely certain and it is also vaporized after a while. Ants are able to detect Pheromone existence through their smell sense. Similarly, among two paths, they select the path which has had more Pheromone concentration. Assume that there have been two paths between formic arm and a food source, one of them is shorter. One of the ants selects the shorter path and the other selects the longer path and these selections are completely in random. Both ants leave their Pheromone trace in the path. Certainly, the ant which goes the shorter path, attains the food source sooner and gets some food and returns to formic arm. When it reaches the formic arm, puts the food and goes to the food source again. However, the ant which goes the long path maybe in the path of going to food source, so it returns the formic arm later than the ant with shorter path. Then the shorter path will have more Pheromone in itself and other ants that seek a path to find food source will select the shorter path, because it has more concentration of Pheromone. Therefore, after passing a certain time, almost the majority of ants go to the shorter path. In the following, according to the mentioned properties for ants, it will deal with expressing the structure of algorithm ACO [39].

\subsection{Structure of ant colony optimization algorithm}

Assume that ant colony is included $\mathrm{N}$ ants. Ants start moving from the formic arm according to Figure 1. In in each repetition of period, each ant will go a path from the first to the last layer to reach the destination (food). Based on the following equation, each ant in each layer only can select one option with the possibility of $\mathrm{P}_{\mathrm{ij}}$.

$$
P_{i j}{ }^{K}= \begin{cases}\frac{\left(\tau_{i j}\right)^{\alpha}}{\sum_{j \in N i}\left(\tau_{i j}\right)^{\alpha}} & \text { if } j \in N i \\ 0 & \text { if } j \nexists N i\end{cases}
$$

That $\tau_{\mathrm{ij}}$ is the intensity of Pheromone left in the ijth path. $\alpha$ implies the significance of Pheromone. Ni shows the number of places adjacent for $k$ th ant, and $\mathrm{j}$ is the next place for the $\mathrm{kth}$ ant.

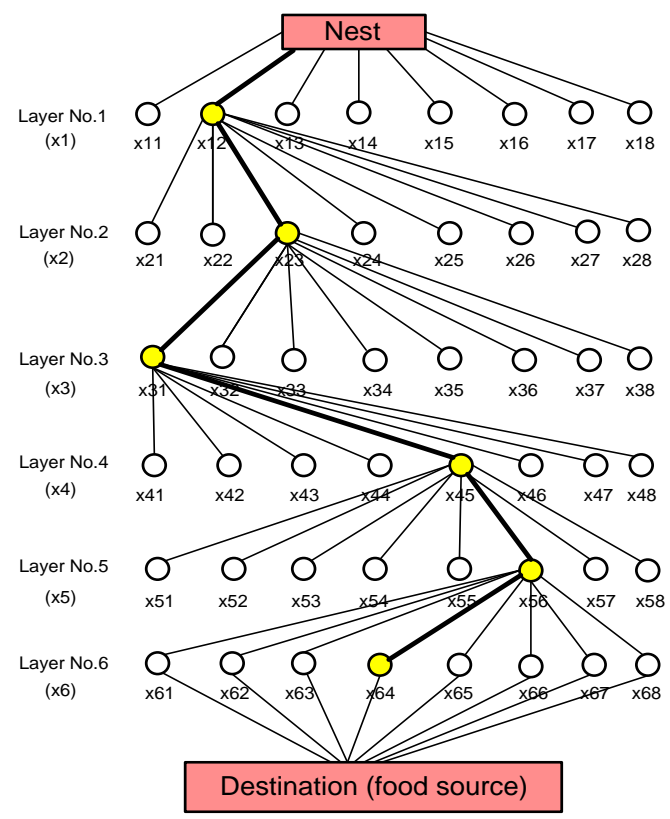

Figure 1. Method of finding the path between formic arm to food source in a multi-variable problem by ants 
At beginning the process of optimizing all path have primary Pheromone concentration. As it has been shown in Figure 1, ants have started moving from their formic arm and seek a value for variable in each layer randomly. In each repetition, each ant will pass an answer vector (the path goes by ant) that includes seeking variables that is between formic arm and food. This seeking is continued to the maximum repetition. The value of each variable is selected based on the path, which has the most Pheromone as the element of answer vector optimization, and finally in the optimal answer, nearly all ants select the best path, which has the most Pheromone. When the kth ants is placed in the location $i$, uses the $\tau_{\mathrm{ij}}$ Pheromone value to select the next place (jth place) that the possibility of selecting each place will be computed from Eq. (13). The points selected during the traversed path by each ant is the candidate to answer the problem. For example, a path traversed by the kth ant has been prominent that the answers $\mathrm{X} 12, \mathrm{X} 23, \mathrm{X} 31, \mathrm{X} 45, \mathrm{X} 56$ and X64 make a complete path between formic arm and food source. Each ant leaves some Pheromone in the path it passed. The following formula shows the increase in Pheromone concentration after each ant traversing between places $i$ and $j$ [39].

$$
\tau_{i j}^{(k)} \leftarrow \tau_{i j}^{(k-1)}+\Delta \tau^{(k)}
$$

When kth ant moves in a path, Pheromone in all path will be evaluated with the following formula:

$$
\tau_{i j} \leftarrow(1-\rho) \tau_{i j} \forall(i, j) \in A
$$

in which, $\mathrm{p}$ is evaporation factor and the value in the interval $(\mathrm{O}, 1]$. $\mathrm{A}$ is the path crossed from formic arm to food source. Considering the evaporation factor causes to omit weaker answers and this will lead to dynamism of seeking process, because maybe there are another shorter path. A repetition of the seeking process includes ants movement, Pheromone evaluation and the value of remainder Pheromone. After returning to formic arm, Pheromone information will be updated based on below formula:

$$
\tau_{i j}=(1-\rho) \tau_{i j}+\sum_{k=1}^{N} \Delta \tau_{i j}{ }^{(k)}
$$

in which, $\Delta \tau_{i j}$ is the value of reminder Pheromone on the arc $i j$ by the $k$ superior ant. The Pheromone left on the path $i j$ is obtained through the best ant as follow:

$$
\Delta \tau_{i j}^{(k)}=\frac{Q}{L_{k}}
$$

in which, Q is a constant value and Lk is the length of path traversed by Kth ant (about travel from a city to another city in the problem of hawker). Eq. (16) can be performed as follow:

$$
\Delta \tau_{i j}^{(k)}=\left\{\begin{array}{cr}
\frac{a f_{\text {best }}}{f_{\text {worst }}} ; & \text { if }(i, j) \in \text { globalbest tour } \\
0 ; & \text { otherwise }
\end{array}\right.
$$

in which, $f_{\text {worst }}$ is the worst value and $f_{\text {best }}$ the best value of objective function among the path crossed by $\mathrm{N}$ ant, and $\beth$ is a parameter to control the overall updating scale of Pheromone. The larger this value, more Pheromone will be aggregated on the best path and seek better algorithm in local optimum and will find the real optimum, so it won't involve in local optimums.
Ant Colony Optimization algorithm that has been used to solve a minimizing problem step by step, is expressed as follow briefly [39]:

\section{First step:}

Assume that there is $\mathrm{N}$ ant in the colony and for each $\mathrm{n}$ variable, the places are determined which includes allowed discrete value. The allowed discrete value of the variable $\mathrm{Xi}$ is expressed as Xi1, Xi2, .., Xip (i=1, 2, ., n). Assume that $\tau_{\mathrm{ij}}$ is the primary value of pheromone in all path of Figure 2. Superscript $\tau_{\mathrm{ij}}$ expresses the repetition number. For example, $\tau_{\mathrm{ij}}(1)=1$ can be considered for all variables in the first repetition

\section{Second step:}

A) Computing the possibility of selecting the next path or discrete value for the variable $\mathrm{X}_{\mathrm{ij}}$

$$
p_{i j}=\frac{\tau_{i j}^{(l)}}{\sum_{m=1}^{p} \tau_{i j}^{(l)}} ; i=1,2, \ldots, n ; j=1,2, \ldots, p
$$

The above equation is similar to Eq. (12) that $\alpha=1$. Larger values are used for $\alpha$.

B) In the next step, the aggregative possibility will be computed by Eq. (18) and through roulette-wheel method, Kth ant can select the best local place randomly, which will be performed as follows:

$\mathrm{N}$ numbers $\mathrm{r} 1, \mathrm{r} 2, \ldots, \mathrm{rN}$ are generated in the limit $(0,1)$ randomly and compared with aggregative possibilities and the ones are selected that have been larger than generation number and the related location will be posed as the best local place.

\section{Third step:}

A) Repeat the step $2 \mathrm{~B}$ for all variables $i=1,2, \ldots, n$

B) Evaluating the objective function by the values corresponding with a complete path (vector $\mathrm{X}(\mathrm{k})$ or values of xij for all variables by the Kth ant)

$$
f_{k}=f\left(X^{(k)}\right) ; k=1,2, \ldots, N
$$

The best and worst selective path among $\mathrm{N}$ path by ants:

$$
\begin{gathered}
f_{\text {best }}=\min \left\{f_{k}\right\} \quad k=1,2, \ldots, N \\
f_{\text {worst }}=\max \left\{f_{k}\right\} \quad k=1,2, \ldots, N
\end{gathered}
$$

\section{Fourth step:}

Convergence testing) the process of convergence happens when nearly all ants select the best path. If the convergence does not attain, it is assumed that all ants return to formic arm and again start looking for food. In this state, one repetition will be added $(1=1+1)$. In addition, pheromone (or discrete values for variables) will be updated on the path as follow:

$$
\tau_{i j}{ }^{(l)}=\tau_{i j}{ }^{(o l d)}+\sum_{k=1}^{N} \Delta \tau_{i j}{ }^{(k)}
$$

in which, $\tau_{\mathrm{ij}}$ (old) is the value of pheromone in the previous repetition (1-1) th, that this value will be obtained through the following formula:

$$
\tau_{i j}^{(o l d)}=(1-\rho) \tau_{i j}^{(l-1)}
$$

In addition, $\Delta \tau_{\mathrm{ijk}}$ is the pheromone left by the Kth superior ant and the sum of pheromone will be considered on all the gone path (if several ants present the similar superior path). Pay attention that there is only one path that is the superior path for the ith variable. Evaluation rate or evaporation factor 
$\rho_{\text {is }}$ in the limit 0.5 to 0.8 .

The algorithm with the new value $\tau_{\mathrm{ij}}(1)$ returns to the second step. The steps 3, 2 and 4 will be repeated till the convergence time. The convergence attains when all ants select a path similar to the best path. In some cases, process repetition will be stopped after accomplishing the maximum number of repetition (lmax). In the Figure 2, the general flowchart of Ant Colony Optimization algorithm has been presented.

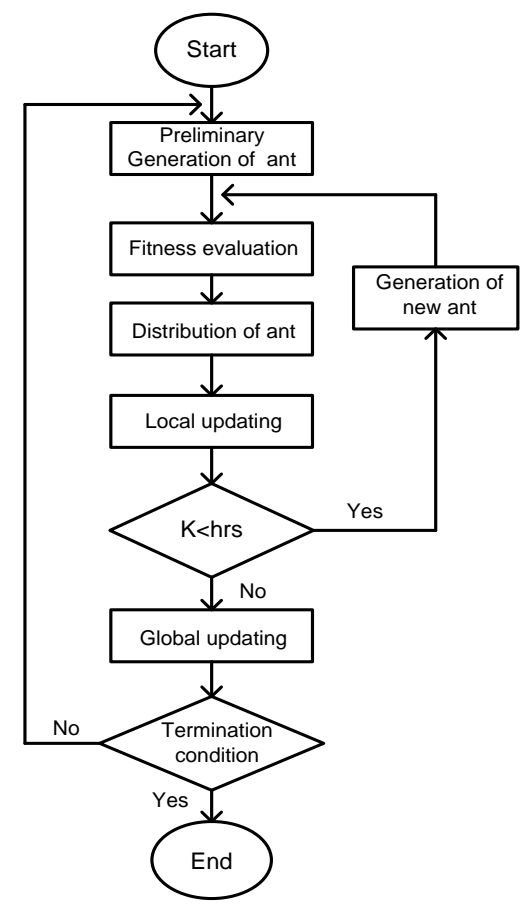

Figure 2. General flowchart of Ant Colony Optimization algorithm

\section{SIMULATION AND RESULTS ANALYSIS}

In this section, a pattern has been presented for power generation of each distributed generation resources. The result of optimization is decrease in power generation costs and minimizing environmental pollutions resulted from distributed generations. In order to attain this objective, the Ant algorithm method has been used. This algorithm not only should seek optimal variables but also act to fulfil the provisions related to power generation of each resources. In this paper, the recommended method is applied on a sample microgrid.

\section{1 studying microgrid model}

The unilinear diagram of the studying weak voltage microgrid has been shown in the Figure 3.

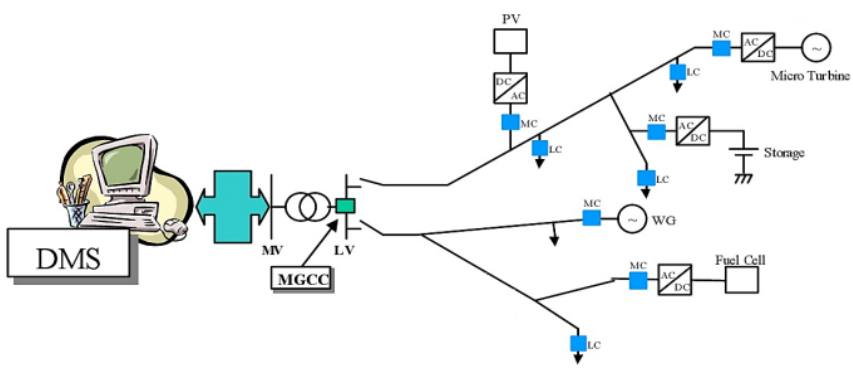

Figure 3. Unilinear model of the studying microgrid
In the studying microgrid, Photo Voltaic (PV), Wind Turbine (WT), Micro Turbine (MT), Fuel Cell (FC) have been used as power generation resources and battery (Bat) as storage resource and power generation in different points of microgrid. Power limitation of each elements of distributed generation is given in Table 1.

Table 1. Limit of changes of distributed generation power

\begin{tabular}{ccccccc}
\hline & Net & Bat & MT & FC & WG & PV \\
\hline lower limit $(\mathrm{kw})$ & -30 & -30 & 6 & 3 & 0 & 0 \\
upper limit(kw) & 30 & 30 & 30 & 30 & 15 & 25 \\
\hline
\end{tabular}

Negative values for battery means storage by battery, also the negative values for grid means selling electricity to the overall grid by microgrid.

In microgrid, some limitations have been considered for power generation by photovoltaic and wind Turbine. In Figure 4 , the value of generation power and wind Turbine has been shown in different hours. In this figure, generation power wind Turbine and photovoltaic has been shown by red curve with star indices and blue carve with circle index. The value of extracted power by each of both elements depends on wind speed and intensity of sun radiation.

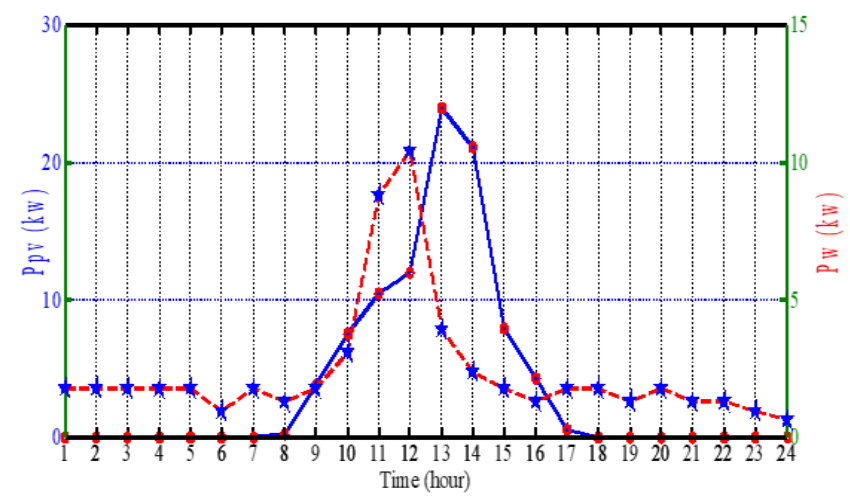

Figure 4. Value of solar and wind generation power

Loads are diffused in microgrid. The value of sum of local loads as well as the cost of each kilowatt hour electric energy are varied, in 24 hours that these values have been shown in Figure 5.

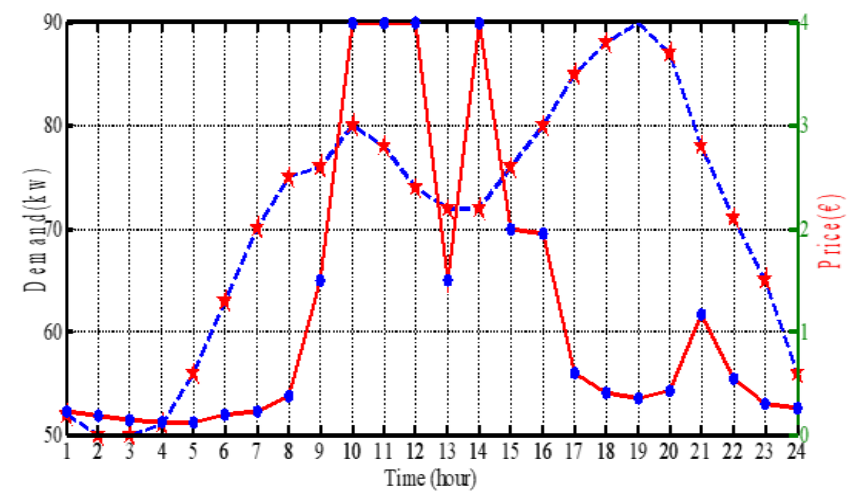

Figure 5. Load changes and cost of electricity in day and night

In the Figure 5, the blue dashed line with star index shows the value of demanded load in different hours and the red line with circle indices 8 also imply the cost of electric energy in 
different hours. Studies have been conducted in both scenarios and each scenario in two sections. In the first scenario, energy management will be conducted for all distributed generation resource and in the second scenario, it is assumed that wind and solar products generated their maximum power and energy management is done for the other elements. In each scenario, decrease in cost as well as decrease in pollution have been studied as two separate objectives. Cost of generation energy of each distributed products have been given in Table 2 with respect to euro on kilowatt/hour. For fuel cell, step up cost has been considered 1.65 euro and 0.96 euro for micro turbine cost.

Table 2. Cost of resource power generation [40]

\begin{tabular}{ccccccc}
\hline & Bat & FC & FC & c & WT & PV \\
\hline $\begin{array}{c}\text { Cost of power } \\
\text { generation } \\
(€ / \text { KWh })\end{array}$ & 0.38 & 0.29 & 0.29 & 0.47 & 1.07 & 2.58 \\
\hline
\end{tabular}

The value that has been considered for solar and wind products, sum of primary investment costs, costs of repair and maintenance that the consumers should pay during exploitation time depended on the value of their generation power in order to compensate the costs.

Similarly, the value of pollution of each power generation has been given in Table 3 for each kilowatt electric power. In this paper three important pollutants $\mathrm{CO}_{2}, \mathrm{SO}_{2}$ and $\mathrm{NOx}$ have been considered and other pollutants have been neglected.

Table 3. Value of pollution of each power generation resources

\begin{tabular}{ccccccc}
\hline & $\mathrm{MT}$ & $\mathrm{FC}$ & $\mathrm{Net}$ & $\mathrm{PV}$ & $\mathrm{WT}$ & $\mathrm{Bat}$ \\
\hline $\mathrm{CO}_{2}(\mathrm{Kg} / \mathrm{MWh})$ & 700 & 460 & -30 & 0 & 0 & -30 \\
$\mathrm{SO}_{2}(\mathrm{Kg} / \mathrm{MWh})$ & 0.0036 & 0.003 & & 0 & 0 & \\
$\mathrm{NOx}(\mathrm{Kg} / \mathrm{MWh})$ & 0.1 & 0.0075 & 30 & 0 & 0 & 30 \\
\hline
\end{tabular}

The value of pollution of solar and wind products has been considered zero can be the most suitable option to decrease the value of pollution resulted from power generation in microgrid.

In order to confirm the obtained results by Ant Colony Optimization algorithm, we will have a comparison between the results obtained of ACO algorithm and some other algorithms (AMPSO-L, AMPSO-T, CPSO-L, FSAPSO, PSO, GA). ACO algorithm parameters have been given in Table 4.

Table 4. Values of Ant Optimization algorithm parameter

\begin{tabular}{cccccc}
\hline $\begin{array}{c}\text { Number of } \\
\text { Ants }\end{array}$ & Iteration & $\alpha$ & $\mathrm{B}$ & $\rho$ & $\begin{array}{c}\text { Number of } \\
\text { nodes }\end{array}$ \\
\hline 100 & 50 & 0.8 & 0.2 & 0.7 & 1000 \\
\hline
\end{tabular}

\subsection{First scenario}

In this scenario, energy management has been done on all distributed generation resource. Objective functions used in this scenario have been selected the decrease in cost and decrease in pollution. Now, Ant Colony Optimization algorithm should act so that the value of power generation costs or the value of pollution reach its minimum. In following, the results of studies have been given into two parts.

\subsubsection{Decrease in power generation cost in the first scenario}

In this section, our goal is to decrease power generation cost. Therefore, ACO optimization algorithm will act such that only the power generation cost become minimum. After conducting optimization by Ant Colony Optimization algorithm, the values of power of each distributed generation element have been obtained. These results have been given in Figure 6. By considering distributed generation power, the costs of energy providing has been minimized.

20 times running the program, the results obtained of optimization have been stored by ACO algorithm. The least value has been obtained 159.323-euro, the most expense 159.328 and overage cost 159.325 euro in 20 times run. As it is expected, at high cost of electricity, distributed generation power has been responsible to supply electrical energy and in low cost, the needed power of load has been mostly supplied by the grid.

By studying the results obtained in decreasing power generation cost, it can be said that ACO has the least value of cost than other algorithm and genetic algorithm has shown the weakest performance. In the case of standard deviation, we can say that the algorithm which has less standard deviation, has the more suitable and strict performance and has not obtained the optimal answer randomly [41].

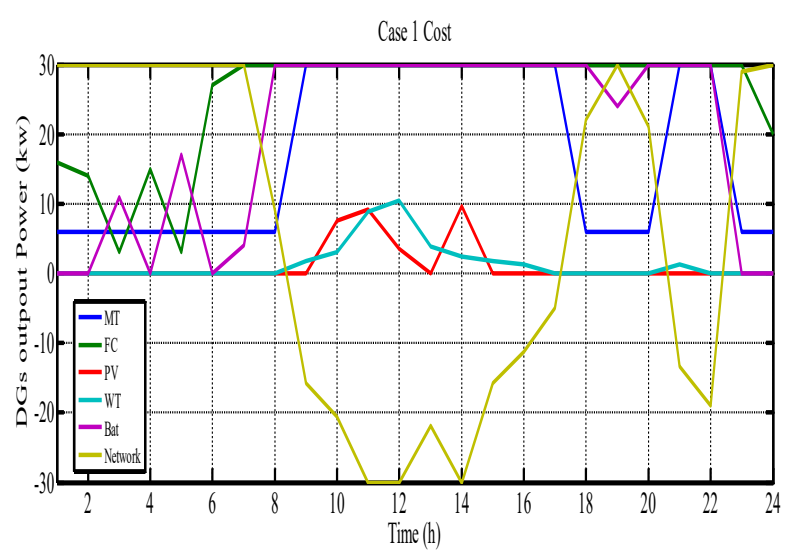

Figure 6. Values of distributed generation power with the objective of decreasing cost in the first scenario

Table 5. Comparing the results of different algorithm in reduce cost

\begin{tabular}{ccccc}
\hline & Best solution $(\boldsymbol{\epsilon})$ & Worst solution($(\boldsymbol{\epsilon})$ & Average $(\boldsymbol{\epsilon})$ & Standard Deviation(€) \\
\hline GA & 162.9469 & 198.5134 & 179.6502 & 24.5125 \\
PSO & 162.0083 & 180.2282 & 171.2103 & 12.6034 \\
FSAPSO & 161.5561 & 175.5402 & 168.2442 & 10.0025 \\
CPSO-T & 161.0580 & 165.3110 & 162.9845 & 2.9971 \\
CPSO-L & 160.7708 & 163.5512 & 162.1614 & 1.9660 \\
AMPSO-T & 159.9244 & 160.4091 & 160.2368 & 0.3427 \\
AMPSO-L & 159.3628 & 159.56813 & 159.5143 & 0.0963 \\
ACO & 159.323 & 159.328 & 159.25 & 0.0658 \\
\hline
\end{tabular}




\subsubsection{Reducing environmental pollution in the 1st scenario}

One of the debatable subjects in microgrid is the discussion of environmental pollutions of equipment of distributed generation in it. In this section, reducing the pollution resulted from microgrid, is the objective of optimization problem. ACO algorithm determines distributed generation power so that it minimizes the pollution resulted from supplying power. After optimization with the objective of reducing pollution, the value of generation power of each power generation resource has been obtained as Figure 7.

The value of pollution made with pattern selection has been $431.248 \mathrm{~kg}$ as Table 4-6. Similarly, in 20 runs of Ant Colony Optimization algorithm, the worst answer has been obtained $431.327 \mathrm{~kg}$. The average value of pollution has been computed $431.287 \mathrm{~kg}$ in 20 runs of the algorithm.

With the results obtained of optimization in 24 hour it can be said that; this algorithm tries to use distributed generation with high pollution less, and this equipment becomes active with its minimum power value, and they will be used when other equipment is disabled in supplying the needed power of load. Among them, microturbine have maintained the least value although it has the most pollution. Similarly, wind and solar power generate their maximum power due to lack of pollution. In Table 6 the comparison has been conducted between the results obtained of optimization by Ant Colony algorithm and another algorithm.

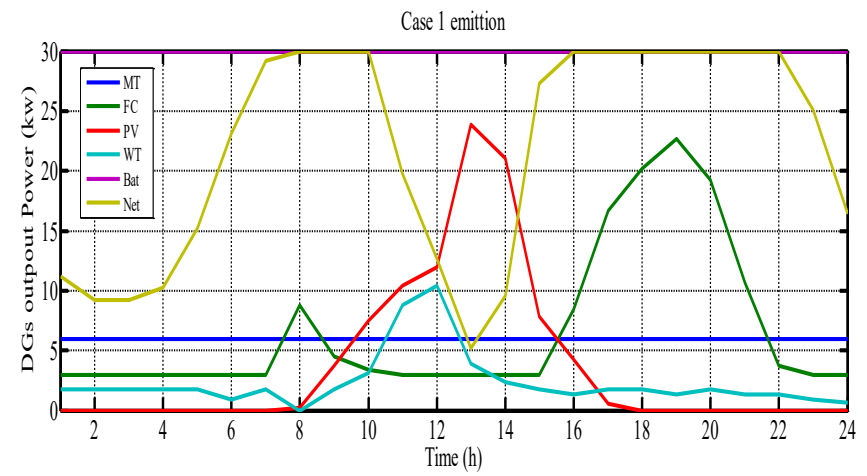

Figure 7. Values of distributed generation with the objective of reducing pollution is the 1 st scenario

Table 6. Comparing the results of different algorithm in reducing pollution

\begin{tabular}{ccccc}
\hline & Best solution $(\mathbf{K g})$ & Worst solution $(\mathbf{K g})$ & Average $(\mathbf{K g})$ & Standard Deviation $(\mathbf{K g})$ \\
\hline GA & 435.2363 & 457.4680 & 445.3862 & 14.2299 \\
PSO & 435.8227 & 454.5917 & 445.1072 & 13.9708 \\
FSAPSO & 435.0830 & 451.3821 & 443.4396 & 11.6525 \\
CPSO-T & 434.9973 & 444.9398 & 440.1036 & 6.9950 \\
CPSO-L & 434.9354 & 443.6383 & 439.2369 & 6.1538 \\
AMPSO-T & 434.8611 & 435.1126 & 434.9983 & 0.1786 \\
AMPSO-L & 434.8193 & 434.0099 & 434.9235 & 0.0681 \\
ACO & 431.248 & 431.327 & 431.287 & 0.0432 \\
\hline
\end{tabular}

\subsection{Second scenario}

In this scenario, it is assumed that wind and solar products, generate their maximum power. This scenario has been conducted as the previous scenario in two sections. In the first section, reducing the costs of power supplying is the subject and the second section, pollution has been reduced. Finally, the results obtained of optimization by Ant Colony Optimization algorithm has been compared with other algorithm.

\subsubsection{Reducing cost of power generation in the second scenario}

After optimizing by Ant Colony Optimization algorithm with the objective of reducing costs of power generation, the values of generation power have been shown in Figure 8 in each hour of each distributed generation resources with the power exchanged with grid.

According to the prerequisite of maximum extraction power of two solar and wind resources, the values of other elements have been selected so that the costs are in their least value. Like the first scenario, optimization has been run 20 times and the obtained results have been presented in Table 7 .

In this section of the second scenario, cost minimum value has been obtained 272.8 euro by Ant Colony Optimization algorithm. After reviewing the obtained results, it can be said that considering such prerequisite will increase the power generation costs. Because the cost of solar and wind generation is always constant and they are not economical, if we want to use them in low load hours which the price of electric energy is low. This will leaded to increase of costs.

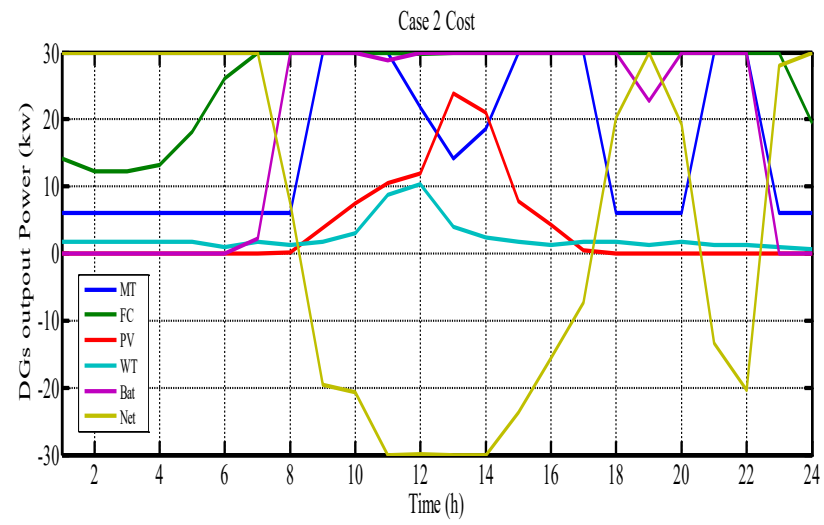

Figure 8. Values of distributed generation power with the objective of reducing cost in the second scenario

5.3.2 Decrease in environmental pollution in the second scenario

In this section of the second scenario, the objective is to decrease pollutions resulted from supplying power in microgrid. Managing the distributed generation power has been conducted in order to minimize the pollution. The value of generation power has been shown in Figure 9 for each studying elements in 24 hours.

The value of pollution has been obtained $431.639 \mathrm{~kg}$ while energy management by ACO algorithm that has been nearly equaled the value of pollution in the second section. The reason of proximity of these two numbers is that to have the least pollution, solar and wind products with zero pollution should generate their maximum power, so this is caused the 
proximity of the results. The reason of the insignificant difference in these two sections is also in the random primary selections of the algorithm. The results obtained by other algorithm and ACO algorithm have been presented in Table 8.

Table 7. Comparing the results of different algorithm in reducing cost in the second scenario

\begin{tabular}{ccccc}
\hline & Best solution (Kg) & Worst solution (Kg) & Average (Kg) & Standard Deviation (Kg) \\
\hline GA & 277.7444 & 304.5889 & 290.4321 & 13.4421 \\
PSO & 277.3237 & 303.3791 & 288.8761 & 10.1821 \\
FSAPSO & 276.7867 & 291.7562 & 280.6844 & 8.3301 \\
CPSO-T & 275.0455 & 286.5709 & 277.4045 & 6.2341 \\
CPSO-L & 274.7438 & 281.1187 & 274.9821 & 5.9697 \\
AMPSO-T & 274.5507 & 275.0905 & 274.9821 & 0.3210 \\
AMPSO-L & 274.5507 & 274.7318 & 274.5643 & 0.0921 \\
ACO & 272.4374 & 272.7454 & 272.4423 & 0.0876 \\
\hline
\end{tabular}

Table 8. Comparing the results of different algorithm in reducing pollution in the second scenario

\begin{tabular}{ccccc}
\hline & Best solution (Kg) & Worst solution (Kg) & Average (Kg) & Standard Deviation (Kg) \\
\hline GA & 435.1308 & 448.7740 & 441.2402 & 5.2689 \\
PSO & 435.5555 & 438.2212 & 436.5928 & 1.2666 \\
FSAPSO & 435.0037 & 437.1788 & 436.0913 & 1.5380 \\
CPSO-T & 434.0037 & 436.9001 & 436.0913 & 1.3567 \\
CPSO-L & 434.9064 & 436.3830 & 435.9408 & 1.0441 \\
AMPSO-T & 434.8611 & 435.0102 & 435.6447 & 0.1054 \\
AMPSO-L & 434.8161 & 434.9690 & 434.9357 & 0.0586 \\
ACO & 431.6391 & 431.7268 & 431.6723 & 0.0531 \\
\hline
\end{tabular}

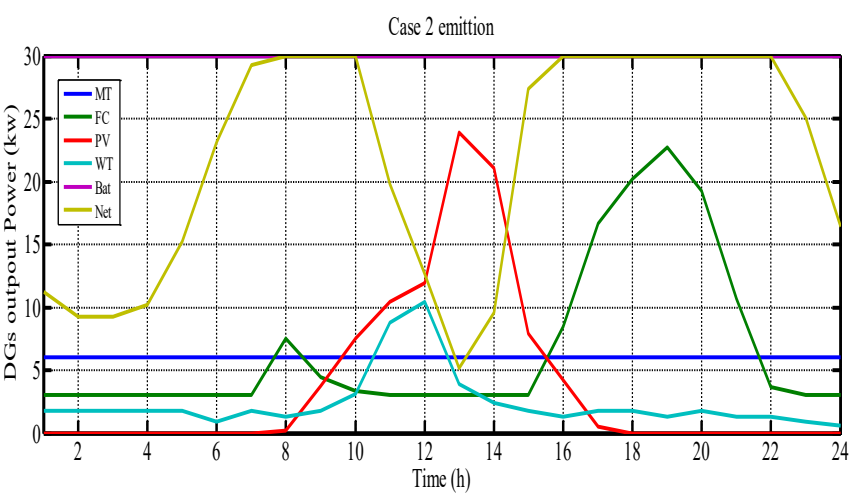

Figure 9. Values of distributed generation power with the objective of reducing pollution in the second scenario

\section{CONCLUSION}

Using renewable energy resources in energy distribution grids with the title of distributed generation for low and distributed consuming loads in faraway regions such as faraway villages and low pollution islands can be suitable strategies to decrease economical expenses and environmental pollution and to increase energy efficiency. Similarly, since the most important objective of using renewable energy resources, is to decrease the costs, so it is necessary to study strict economical subjects for the given distribution grids and the type of necessary energy resources to supply consuming loads and the value of generated energy should be considered according to other parameter such as type and size of consuming loads and their change rate, cost of building and exploiting wind or solar power plant, etc. and comparing with the cost of consuming fuel of power plants, cost of building and exploiting general power grid in the region and consuming electricity rate by subscribers, geographical condition of environment to use different possible renewable energy, etc. On the other hand, the growing trend of individualization, competitiveness of the electricity market and converting big investors into small investors, lead power industry managers to pay attention into increase generation power and grid equipment with maximum energy efficiency and minimum cost of exploitation more than before.

The objective of this paper is to manage optimal exploitation from microgrids by considering the capacity available in power market. The exploiter of the microgrid who is in fact responsible for secure exploitation of this grid, should consider programming in this grid in order to consider all components of microgrid. On the other words, sufficient confidence is made for generation resources of these grids in order to reduce cost and emission of environmental pollution obtained of energy generation. To attain this important point, Ant Colony Optimization algorithm has been used to minimize the costs and environmental pollution resulted from electrical power generation by presenting a suitable pattern for power generation by distributed generation. The results of simulation were conducted in both sections, decrease in cost and pollution by Ant Colony Optimization algorithm and the results of other algorithm were compared that in all condition, the recommended algorithm of this paper, namely ACO algorithm have had more suitable performance in decreasing objective function.

\section{REFERENCES}

[1] Lidula, N.W.A., Rajapakse, A.D. (2011). Microgrids research: A review of experimental microgrids and test systems. Renewable and Sustainable Energy Reviews, 15(1):

186-202.

https://doi.org/10.1016/j.rser.2010.09.041

[2] Chowdhury, S., Crossley, P. (2009). Microgrids and active distribution networks. The Institution of Engineering and Technology. http://doi.org/10.1049/PBRN006E

[3] Marnay, C., Asano, H., Papathanassiou, S., Strbac, G. (2008). Policymaking for microgrids. IEEE Power and Energy Magazine, 6(3): 66-77. 
https://doi.org/10.1109/MPE.2008.918715

[4] Tsikalakis, A.G., Hatziargyriou, N.D. (2011). Centralized control for optimizing microgrids operation. 2011 IEEE Power and Energy Society General Meeting, Detroit, MI, USA, pp. 1-8. https://doi.org/10.1109/PES.2011.6039737

[5] Katiraei, F., Itavani, R., Hatziargyriou, N., Dimeas, A. (2008). Micro grid management. IEEE Power and Energy Magazine, 6: 54-65. http://doi.org/10.1109/MPE.2008.918702

[6] Pecas Lopes, J.A., Madureira, A. (2007). Advanced Architectures and Control Concepts for more Microgrids, Work Pacage D-DDI. INESC porto, 2007.

[7] Gu, W., Wu, Z., Bo, R., Liu, W., Zhou, G., Chen, W., $\mathrm{Wu}, \mathrm{Z}$. (2014). Modeling, planning and optimal energy management of combined cooling, heating and power microgrid: A review. International Journal of Electrical Power \& Energy Systems, 54: 26-37. https://doi.org/10.1016/j.ijepes.2013.06.028

[8] Prodan, I., Zio, E. (2014). A model predictive control framework for reliable microgrid energy management International Journal of Electrical Power \& Energy Systems, 61: 399-409. https://doi.org/10.1016/j.ijepes.2014.03.017

[9] Parisio, A., Rikos, E., Tzamalis, G., Glielmo, L. (2014). Use of model predictive control for experimental microgrid optimization. Applied Energy, 115: 37-46. https://doi.org/10.1016/j.apenergy.2013.10.027

[10] Dimeas, A.L., Hatziargyriou, N.D. (2005). Operation of a multiagent system for microgrid control. IEEE Transactions on Power systems, 20(3): 1447-1455. https://doi.org/10.1109/TPWRS.2005.852060

[11] Funabashi, T., Tanabe, T., Nagata, T., Yokoyama, R. (2008). An autonomous agent for reliable operation of power market and systems including microgrids. 2008 Third International Conference on Electric Utility Deregulation and Restructuring and Power Technologies, Nanjing, China, pp. 173-177. https://doi.org/10.1109/DRPT.2008.4523397

[12] Duan, R., Deconinck, G. (2011). Market mechanism of smart grids: multi-agent model and interoperability. 2011 International Conference on Networking, Sensing and Control, Delft, Netherlands, pp. 8-13. https://doi.org/10.1109/ICNSC.2011.5874930

[13] Bhuvaneswari, R., Srivastava, S.K., Edrington, C.S., Cartes, D.A., \& Subramanian, S. (2010). Intelligent agent based auction by economic generation scheduling for microgrid operation. 2010 Innovative Smart Grid Technologies (ISGT), Gaithersburg, MD, USA, pp. 1-6. https://doi.org/10.1109/ISGT.2010.5434745

[14] Logenthiran, T., Srinivasan, D., Khambadkone, A.M. (2011). Multi-agent system for energy resource scheduling of integrated microgrids in a distributed system. Electric Power Systems Research, 81(1): 138148. https://doi.org/10.1016/j.epsr.2010.07.019

[15] Boqiang, R., Chuanwen, J. (2009). A review on the economic dispatch and risk management considering wind power in the power market. Renewable and Sustainable Energy Reviews, 13(8): 2169-2174. https://doi.org/10.1016/j.rser.2009.01.013

[16] Hernandez-Aramburo, C.A., Green, T.C., Mugniot, N. (2005). Fuel consumption minimization of a microgrid. IEEE Transactions on Industry Applications, 41(3): 673681. https://doi.org/10.1109/TIA.2005.847277
[17] Eslami, E., Ahmadi Kamarposhti, M. (2019). Optimal design of solar-wind hybrid system-connected to the network with cost-saving approach and improved network reliability index. SN Appl. Sci., 1: 1742. https://doi.org/10.1007/s42452-019-1710-y

[18] Hatziargyriou, N.D., Anastasiadis, A.G., Vasiljevska, J., Tsikalakis, A.G. (2009). Quantification of economic, environmental and operational benefits of microgrids. 2009 IEEE Bucharest PowerTech, Bucharest, Romania, pp. 1-8. https://doi.org/10.1109/PTC.2009.5281860

[19] Mohamed, F.A., Koivo, H.N. (2007). System modelling and online optimal management of microgrid using multiobjective optimization. International Conference on Clean Electrical Power. Capri, Italy, 2007, pp. 148-153, https://doi.org/10.1109/ICCEP.2007.384202

[20] Mazidi, M., Zakariazadeh, A., Jadid, S., Siano, P. (2014). Integrated scheduling of renewable generation and demand response programs in a microgrid. Energy Conversion and Management, 86: 1118-1127. https://doi.org/10.1016/j.enconman.2014.06.078

[21] Ahmadi Kamarposhti, M. (2018). Optimal control of islanded micro grid using particle swarm optimization algorithm. International Journal of Industrial Electronics Control and Optimization. 1(1): 53-60. http://doi.org/10.22111/IECO.2018.24354.1022

[22] El-Khattam, W., Salama, M.M. (2004). Distributed generation technologies, definitions and benefits. Electric Power Systems Research, 71(2): 119-128. https://doi.org/10.1016/j.epsr.2004.01.006

[23] Cardoso, G., Stadler, M., Siddiqui, A., Marnay, C., DeForest, N., Barbosa-Póvoa, A., Ferrão, P. (2013). Microgrid reliability modeling and battery scheduling using stochastic linear programming. Electric Power Systems Research, 103: 61-69. https://doi.org/10.1016/j.epsr.2013.05.005

[24] Hemmati, M., Amjady, N., Ehsan, M. (2014). System modeling and optimization for islanded micro-grid using multi-cross learning-based chaotic differential evolution algorithm. International Journal of Electrical Power \& Energy Systems, 56: 349-360. https://doi.org/10.1016/j.ijepes.2013.11.015

[25] Sechilariu, M., Wang, B.C., Locment, F. (2014). Supervision control for optimal energy cost management in DC microgrid: Design and simulation. International Journal of Electrical Power \& Energy Systems, 58: 140149. https://doi.org/10.1016/j.ijepes.2014.01.018

[26] Parisio, A., Rikos, E., Glielmo, L. (2014). A model predictive control approach to microgrid operation optimization. IEEE Transactions on Control Systems Technology, 22(5): 1813-1827. https://doi.org/10.1109/TCST.2013.2295737

[27] Zakariazadeh, A., Jadid, S., Siano, P. (2014). Stochastic multi-objective operational planning of smart distribution systems considering demand response programs. Electric Power Systems Research, 111: 156168. https://doi.org/10.1016/j.epsr.2014.02.021

[28] Mohammadi, S., Soleymani, S., Mozafari, B. (2014). Scenario-based stochastic operation management of microgrid including wind, photovoltaic, micro-turbine, fuel cell and energy storage devices. International Journal of Electrical Power \& Energy Systems, 54: 525535. https://doi.org/10.1016/j.ijepes.2013.08.004

[29] Marzband, M., Ghadimi, M., Sumper, A., DomínguezGarcía, J. L. (2014). Experimental validation of a real- 
time energy management system using multi-period gravitational search algorithm for microgrids in islanded mode. Applied Energy, 128: 164-174. https://doi.org/10.1016/j.apenergy.2014.04.056

[30] Nezhad, A.E., Javadi, M.S., Rahimi, E. (2014). Applying augmented $\varepsilon$-constraint approach and lexicographic optimization to solve multi-objective hydrothermal generation scheduling considering the impacts of pumped-storage units. International Journal of Electrical Power \& Energy Systems, 55: 195-204. https://doi.org/10.1016/j.ijepes.2013.09.006

[31] Guo, L., Liu, W., Cai, J., Hong, B., Wang, C. (2013). A two-stage optimal planning and design method for combined cooling, heat and power microgrid system. Energy Conversion and Management, 74: 433-445. https://doi.org/10.1016/j.enconman.2013.06.051

[32] Shayeghi, H., Sobhani, B. (2014). Integrated offering strategy for profit enhancement of distributed resources and demand response in microgrids considering system uncertainties. Energy Conversion and Management, 87: 765-777.

https://doi.org/10.1016/j.enconman.2014.07.068

[33] Wang, Z., Chen, B., Wang, J., Begovic, M.M., Chen, C. (2014). Coordinated energy management of networked microgrids in distribution systems. IEEE Transactions on Smart Grid, 6(1): 45-53. https://doi.org/10.1109/TSG.2014.2329846

[34] Kuznetsova, E., Ruiz, C., Li, Y.F., Zio, E. (2015). Analysis of robust optimization for decentralized microgrid energy management under uncertainty. International Journal of Electrical Power \& Energy Systems, 64:

$815-832$.
[35] Hytowitz, R.B., Hedman, K.W. (2015). Managing solar uncertainty in microgrid systems with stochastic unit commitment. Electric Power Systems Research, 119: 111-118. https://doi.org/10.1016/j.epsr.2014.08.020

[36] Su, W., Wang, J., Roh, J. (2013). Stochastic energy scheduling in microgrids with intermittent renewable energy resources. IEEE Transactions on Smart grid, 5(4): 1876-1883. https://doi.org 10.1109/TSG.2013.2280645

[37] Ji, L., Niu, D.X., Huang, G.H. (2014). An inexact twostage stochastic robust programming for residential micro-grid management-based on random demand. Energy, 67: 186-199. https://doi.org/10.1016/j.energy.2014.01.099

[38] Niknam, T., Golestaneh, F., Shafiei, M. (2013). Probabilistic energy management of a renewable microgrid with hydrogen storage using self-adaptive charge search algorithm. Energy, 49: 252-267. https://doi.org/10.1016/j.energy.2012.09.055

[39] Chakraborty, S., Weiss, M.D., \& Simoes, M.G. (2007). Distributed intelligent energy management system for a single-phase high-frequency AC microgrid. IEEE Transactions on Industrial Electronics, 54(1): 97-109. https://doi.org/10.1109/TIE.2006.888766

[40] Battiti, R., Brunato, M. (2007). Approximation Algorithms and Metaheuristics. Reactive Search: Machine Learning for Memory-Based Heuristics, CRC Press.

[41] Moghaddam, A.A., Seifi, A., Niknam, T., Pahlavani, M.R.A. (2011). Multi-objective operation management of a renewable MG (micro-grid) with back-up microturbine/fuel cell/battery hybrid power source. Energy, 36(11): 6490-6507. https://doi.org/10.1016/j.energy.2011.09.017 